Sebelas Maret Business Review Vol. 4 Issue 1, pp. 35 - 46

ISSN: 2528-0627 (print) / 2528-0635 (online)

Copyright ( Magister Manajemen Universitas Sebelas Maret

Homepage: https://jurnal.uns.ac.id/smbr

\title{
The Effectiveness of Design Thinking Training in Increasing Intention of Innovative Behavior and Creativity
}

\author{
Hajan Hidayat* \\ Department of Business Management, Politeknik Negeri Batam, Indonesia
}

\begin{abstract}
This study aims to empirically examine the effectiveness of design thinking training to improve the intention to behave innovatively and creatively. The research method used to carry out this research is the Quasi Experiment Method. The results of hypothesis testing using t-test showed that there was no significant difference in creativity scores between before and after the training treatment. This shows that Design Thinking training is not effective in increasing creativity. However, the two alternative hypotheses were tested using t-test showed that there were significant differences scores of innovative behavior intention before and after treatment of Design Thinking. This shows that Design Thinking training is effective in increasing the intention to behave innovative. This research is expected to contribute studies on the effectiveness of the Design Thinking training method and produce a training module that can be used in the entrepreneurial learning process. Based on the results of this study, Design Thinking training can be used as a method to encourage innovative behavior.
\end{abstract}

Keywords: Innovative behavior intention, Creativity, Design Thinking, Training

\section{Introduction}

The environment and the challenges of life today is different from the past. Steinbeck (2011) states that throughout the world, situations show that students are not prepared to be able to overcome complex and unstructured problems where they do not have easy answers. Moreover, Steinbeck (2011) states that to meet expectations in the 21 st century, educators need to abandon old ideas and pedagogy and be brave to develop a set of learning changes needed for learners and their work in the future. This means reducing the time to explain through instruction and investing more time in forms of experimentation and student involvement that tolerate mistakes.

The views expressed by Steinbeck (2011) indicate that there are changes in the challenges of today's life and the need for changes in learning methods that are appropriate to these challenges. Compared to the method lecturing, certain learning methods are empirically proven to be more effective in increasing creativity. The results of research conducted by Steinbeck (2011) show that students' creative thinking abilities towards learning mathematics with methods brainstorming are higher than those using computer learning methods. Studies that try to measure the perceptions and attitudes of the development of logic and creative thinking between learning the methods of reading, presenting, and asking with the Experimental and Discussion Methods show that the Experimental and Discussion Method is better in improving the

* Corresponding author at Batam Centre, Jl. Ahmad Yani, Tlk. Tering, Kec. Batam Kota, Kota Batam, Kepulauan Riau 29461 Indonesia. Email: hajan@polibatam.ac.id 
perception and attitude of the development of logic and creative thinking of students (Marušić and Sliško, 2014).

Research conducted by Ersoy and Baser (2014) finds that the effect of teaching methods problem based learning results $i$ is problem based learning effective in enhancing creative thinking abilities. When looking at the learning treatment model used in the two studies above that has proven effective in increasing creativity, the learning model used involves students' participation and collaboration as well as the independence of students in finding and developing knowledge.

What about Design Thinking? Design Thinking into a popular concept these days. The concept Design Thinking was originally introduced by Professor Peter Rowe in 1987. However, the concept Design Thinking began to be widely recognized since the design school was established at Stanford University that used the concept in 2005. Design Thinking was then used as a method of dealing with companies creating innovation by consultants formed by Stanford University named IDEO. Some products that were born from the method Design Thinking such as the mouse computer's first by Apple Inc., Palm V Personal Digital Assistant/ PDA by Palm Inc., and Life Port Kidney Transporter by Organ Recovery Systems Inc. The ability of the method Design Thinking in creating innovative products then encourages the spread of this method.

Although Design Thinking has been widely applied, but as far as the author's knowledge, research on design thinking is still very minimal. More specifically, design thinking as a treatment that is associated with other variables has not been much studied. Steinbeck (2011) states that one of the future studies that need to be developed is how to develop measurement system Design Thinking a more comprehensive including new measures to measure the effect of Design Thinking on the learning process and student learning outcomes from various disciplinary backgrounds.

Wattanasupachoke (2012) examines the effect of design thinking on innovation and company performance. One of his findings is that design thinking has proven to have a positive effect on company innovation. Besides that, design thinking also significantly influences performance positively by being mediated by innovation. The approach design thinking used is to look at the suitability of the process undertaken by the company in developing a product with the characteristics of process design thinking instead of design thinking as a treatment.

The development of the concept and application of design thinking, the lack of research on the influence or benefits of empirical process is design thinking a driving factor for the implementation of this research. The purpose of this study is therefore to empirically examine the effectiveness of training Design Thinking to improve the intentions of innovative behavior and creativity. With the implementation of the research it is hoped that it can add to the study of treatments that can increase the intentions of innovative behavior and creativity while encouraging further exploration of the process Design Thinking. While the benefit practical is the production of training modules that can be used for the learning process.

\section{Theoretical Review and hypothesis development Innovation}

Innovation is the implementation of new products or products that are significantly developed, or interpreted as new processes, marketing methods, and new organizational methods in business practices, organizational workplaces, or external relations (OECD., 2005). Meanwhile, according to (Cox, 2005) innovation is a successful exploitation of new ideas. Innovation is the process that brings these ideas to new products, new services, new ways of doing business or even new ways of doing business.

\section{Creativity}

According to Cox (2005) creativity is generating new ideas, new ways of looking at existing problems and new opportunities, perhaps by utilizing emerging technologies or market changes. Robbins and Judge (2011) state that individual creativity essentially requires expertise, creative thinking skills, and intrinsic motivation for tasks. Furthermore Robbins and Judge (2011) explain in more detail about the three components. Expertise is the basis of all creative work. The potential for creativity is increased when individuals have the ability, knowledge, understanding, and expertise in their fields. 
The second component, namely creative thinking skills, includes personality characteristics related to creativity, the ability to use analogies, and the talent to see something ordinary in different perspectives. While the third component is intrinsic task motivation. Intrinsic task motivation shows a desire to work on something because it is interesting, engaging, exciting, satisfying, or personally challenging.

The ability to think creatively can be improved over time. The ability to think creatively can be improved by providing a conducive environment and treatments such as training and education. Robbins and Judge (2011) described creativity as a skill that can reach the highest level through a training environment that leads to intensive skills, such as swimming, riding a bicycle and racing. While Robbins and Judge (2011) states that creativity skills can be sharpened, not because of natural abilities.

Evidence of the relationship between treatment and creativity is shown by studies that try to investigate the effect of a particular treatment on creativity. The results of research conducted by Wang (2014) show that students' creative thinking abilities towards learning mathematics with methods brainstorming are higher than those using computer learning methods. Studies that try to measure the perceptions and attitudes of the development of logic and creative thinking between learning the methods of reading, presenting, and asking questions with the Experimental and Discussion Methods show that the Experimental and Discussion Method is better in improving the perception and attitude of the development of logic and creative thinking of students (Marušić and Sliško, 2014).

\section{Design Thinking and Training of Design Thinking}

Wang (2014) states that design thinking is generally defined as the process of analysis and creative that involves a person in the opportunity to experiment, creating a model (prototype), receive feedback, and redesign. Design thinking is a learning approach that focuses on developing children's creative selfconfidence through assigned projects that focus on empathy, develop bias through action, encourage the emergence of ideas and develop problem solving abilities actively.

Training Design Thinking is a training whose material is arranged based on the process design thinking. This training material includes activities empathy for problems (empathy), defining problems (define), looking for ideas or solutions to problems (ideate), making models / prototypes of ideas / solutions (prototyping), carrying out model / prototype testing (testing), and which The last is to make the final product based on input or feedback at the stage testing.

Cogent action theory of reasoned action theory (Theory of Reasoned Action) is based on the assumption that a person normally behaves in a way that makes sense, that they consider the information provided and implicitly or explicitly consider the implications of their actions. Theory of Reasoned Action is designed to predict the behavior of the will and to help us understand their psychological determinants. Theory of Reasoned Action (TRA) connects faith (belief), attitude (attitude),intention (intention) and behavior (behavior).Intention is the best predictor of behavior that is if you want to know what someone will do the best way to find out is to know the person's intentions (Ajzen and Fishbein, 1975).

Motivation Theory of Self-Efficacy theory Self-efficacy is one of the contemporary theories of motivation developed by Albert Bandura. According to Robinson and R. J. Bennett (1995) this theory is based on the individual's belief that he is able to carry out the task. self-efficacy Higher is associated with higher self-confidence, higher persistence when facing difficulties, and responding to negative feedback by working harder and not giving up. Furthermore Robinson and R. J. Bennett (1995) explain that self-efficacy can be improved in several ways. The first is to increase mastery of a task or skill. The second is to model our actions after others have been able to effectively carry out and apply their work. The last way is to accept verbal persuasion and also preoccupation when completing the task.

The Effect of Design Thinking on Intentions of Innovative Behavior, (Cox, 2005) states that design connects creativity and innovation. The design forms a practical and attractive offer for users or customers. Design can be described as creativity that is directed towards specific goals. Wattanasupachoke, T, (2012) who examined the effect of design thinking on innovation and company performance. One of his findings is that design thinking has proven to have a positive effect on company innovation. Besides that, design thinking also significantly influences performance positively by being mediated by innovation. 
Innovation is a process multistage. In the initial stages of innovation, individuals need to look for problems and then they gather knowledge related to innovation and try to find out original solutions to solve problems. During the third stage, innovative individuals find sponsors for an idea and attempt to build a supporting coalition for it. Finally, at the last stage, individuals transform ideas or solutions into useful applications that can be balanced or mass produced (Wang, 2014).

Innovation requires a match between the problem and the solution provided. Training Design Thinking trains individuals to provide solutions based on the accuracy of understanding the problems felt by consumers. The ability to be able to understand problems and adjust solutions is an important process in innovation.

Cox (2005) explain about the factors that influence the intention to behave innovative shows that liberalization (freedom) in expressing ideas and solutions influences the intention to behave innovative. In theprocess design thinking, individuals have the freedom to find solutions to the challenges they face. With this freedom, according to Li (2014) findings, the intention to behave innovatively in the design thinking process, individuals will increase. Based on the description above, the first alternative hypothesis proposed is:

H1: There are differences in intentions of innovative behavior between before and after treatment design thinking training

\section{The Effect of Design Thinking on Creativity}

Research conducted by Ersoy and Baser (2014) investigates the influence ofteaching methods problem basedlearning produces findings that teaching problem-based learning is effective in improving creative thinking abilities. The learning approach taken in problem-based learning (PBL) in which students are given problems as learning material, has similarities with theprocess design thinking. Through problems, students are encouraged to generate ideas or solutions to these problems. The situation gave rise to innovation and creativity.

Returning to Robbin and Judge's previous statement that creativity is influenced by three things namely expertise, creative thinking skills, and intrinsic motivation of the task, then design thinking can improve innovative thinking abilities and creativity by building or through self-efficacy. Design thinking encourages participants to find solutions to real problems that they face by carrying out an empathy process for the problem, defining the problem, finding alternative solutions, prototyping solutions, testing and observing weaknesses. The process carried out trains participants to be more sensitive, think flexibly, be motivated to face challenges and be skilled in dealing with problems. Based on the description, the second hypothesis put forward in this research is as follows:

\section{H2: There are differences in creativity between before and after the treatment of design thinking} training

\section{Research Methods}

\section{Variables and Treatment}

The variables examined in this study are the intentions of innovative behavior and creativity. Both variables are measured using the selfmethod-assessment. The treatment given to the experimental group wastraining Design Thinking. The time needed to carry out training is estimated at 13 hours. Details of the time and material of training activities can be seen in table 1. 
Table 1. Allocation of Time and Material of Training Activities Design Thinking Plus

\begin{tabular}{llll}
\hline $\begin{array}{l}\text { Implementation } \\
\text { Time }\end{array}$ & Material & Description & $\begin{array}{l}\text { Allocation } \\
\text { Time }\end{array}$ \\
\hline Day 1 & $\begin{array}{l}\text { Introduction to } \\
\text { Training } \\
\text { Innovation and } \\
\text { Creativity } \\
\text { Design Thinking }\end{array}$ & $\begin{array}{l}\text { Introductory and ice breaking } \\
\text { Exposure on definition, function, processes and } \\
\text { benefits of innovation and creativity }\end{array}$ & $\begin{array}{l}\text { Presentation about the concept, the process of } \\
\text { design thinking }\end{array}$ \\
& Design & $\begin{array}{l}\text { Presentation about the concept and important } \\
\text { aspects in design communication. }\end{array}$ & 1 hours \\
Assignment & $\begin{array}{l}\text { Submitting tasks } \\
\text { design practice thinking } \\
\text { Presentation of practice results }\end{array}$ & 15 minutes \\
Day 2 & Presentation & 2 hours \\
\hline
\end{tabular}

\section{Research Model}

This study uses the experimental method Quasi Experimental. The model used in this study is nonequivalent control group design. The research model can be described as follows.

$$
\frac{Q 1}{Q 3} \times \frac{Q 2}{Q 4}
$$

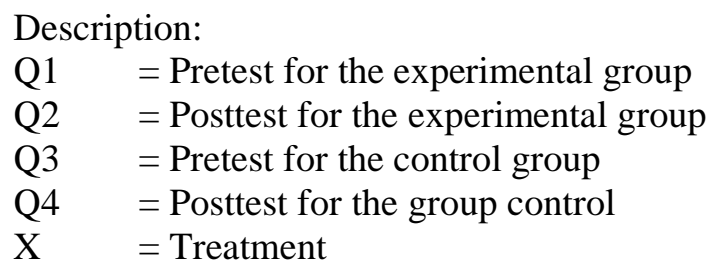

In more detail, in this study the model there are two groups involved in the study of experiments group and the control group. The experimental group was treated as training Design Thinking. While the control group was not treated. Both the experimental group and the control group will be subject to pre-test and post-test. Pretest is a test that is done before the treatment while post-test is a test that is done after the treatment. The pre- and test post-test applied to all groups is an innovative and creative thinking ability test.

\section{Selection of Research Subjects}

The process of selecting research subjects begins with carrying out a pre test to students in the 3 (three) and 5 (five) semesters of several Study Programs at the regular grade State Polytechnic Batam. Thetest was conducted by giving an innovative and creative thinking questionnaire to be filled out. Based on thescores pre-test then categorized creative thinking abilities are categorized as very low, low, medium, high and very high. The determination of these categories is based on scores obtained by subjects from filling out the questionnaire. Based on these categories, research subjects were drawn from students who were in the very low, low, and medium categories. As many as 30 students who entered the low category, 15 students will be included in the experimental group and 15 other students will be included in the control group. The process of selecting research subjects can be illustrated in the following chart 


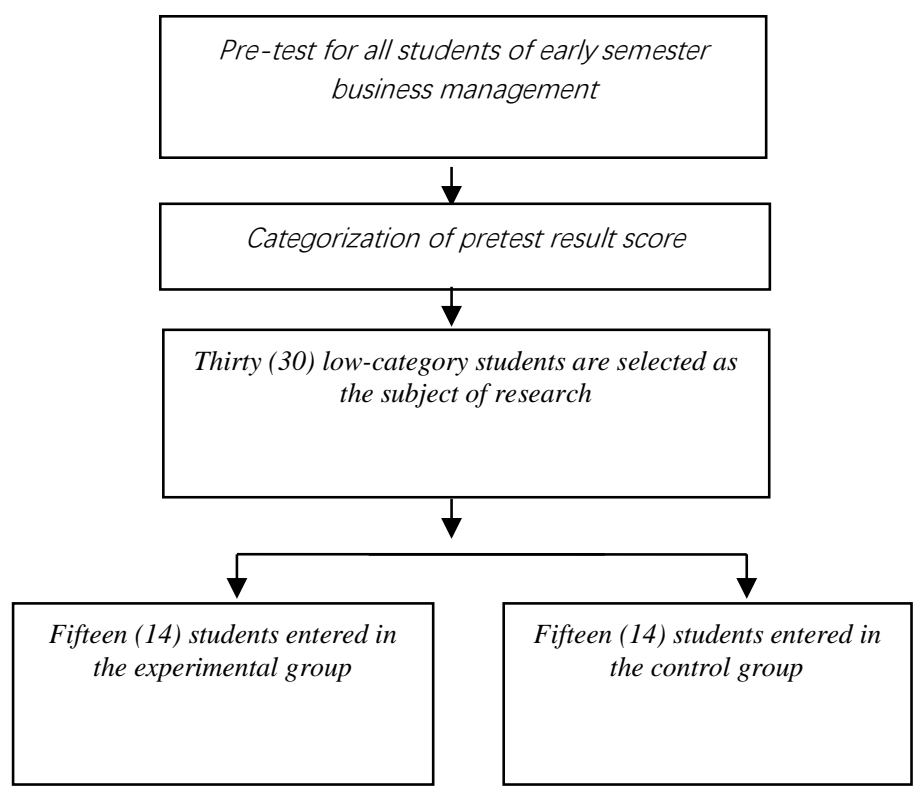

Figure 1. Chart of Research Subject Selection Process

\section{Research Instrument and Subject}

The instrument used was an innovative and creative thinking questionnaire. Before being used for data collection, the two questionnaires were first tested to test their validity and reliability. Subjects numbered 28 (twenty eight) people. Fourteen subjects were included in the control group and 14 were included in the experimental group.

\section{Result}

\section{Questionnaire Test Results}

The results of the validity test on the intention to behave innovative questionnaire showed that all the questionnaire items were valid. Correlation coefficient values for each item ranged from 0.59 to 0.92 . While the validity test results on the creativity questionnaire showed that all the questionnaire items were valid. The correlation coefficient values for each item ranged from 0.34 to 0.71 . Reliability test results of the questionnaire intention innovative behavior and questionnaires creativityusing Cronbach's alpha showing coefficient values of 0.927 and 0.916 . This shows that both questionnaires are reliable.

\section{Pre-Test}

Pretest carried out to measure the level of intention to behave innovative and creativity. The pretest was carried out by distributing questionnaires to 151 students from various study programs at Batam State Polytechnic. Pretest conducted produced two scores, namely the score for the intention to behave innovative variable and the creativity score. The distribution of scores can be seen in table 2 below.

Table 2. Scores Pretest Variable Intension of Behaving Innovative and Creativity

\begin{tabular}{ccccc}
\hline Variable & $\begin{array}{c}\text { Minimum } \\
\text { Score }\end{array}$ & $\begin{array}{c}\text { Maximum } \\
\text { Score }\end{array}$ & $\begin{array}{c}\text { Standard } \\
\text { Deviation }\end{array}$ & $\begin{array}{c}\text { Average } \\
\text { Score }\end{array}$ \\
\hline $\begin{array}{c}\text { Intension of Behaving } \\
\text { Innovative }\end{array}$ & 26 & 63 & 6.96 & 44.41 \\
\hline Creativity & 44 & 105 & 12.09 & 74.84 \\
\hline
\end{tabular}

The score pretest for innovative behavioral intention variables is the minimum score of 26 and the maximum score is 63 . The minimum score for creativity variable is 44 and the maximum score is 105 . The 
average score for innovative behavioral intention variables is 44.41 while the average score for variables creativity is 74.84 . When viewed from the standard deviation values, both in the intention to behave innovative variables and creativity variables, the variation in scores tends to be low.

To better understand overview variable score intention to behave innovative and creativity, the results of pretest students are then grouped into 5 (five) score categories, namely Very Low, Low, Medium, High, and Very High. Table 3 below shows the categorization of scores pretest of students. The intention variable scores of students' innovative behavior was mostly in the high category (45\%). As for the creativity variable, most of the students' scores were also in the high category $(49.7 \%)$.

Table 3. Categorization of Scores Pre-test Student.

\begin{tabular}{|c|c|c|c|c|c|}
\hline \multirow[t]{2}{*}{ Category } & \multirow[t]{2}{*}{ Formula } & \multicolumn{2}{|c|}{$\begin{array}{l}\text { Intention of Behaving } \\
\text { Innovative }\end{array}$} & \multicolumn{2}{|c|}{ Creativity } \\
\hline & & $\mathrm{f}$ & $\%$ & $\mathrm{f}$ & $\%$ \\
\hline Very Low & $\mathrm{X}<\bar{X}$ hipothetics $-1.5 \mathrm{SD}$ & 0 & 0 & 0 & 0 \\
\hline Low & $\begin{array}{c}\bar{X}_{\text {hipothetics-1.5SD }}<\mathrm{X}<\bar{X} \text { hipothetics }-0.5 \\
\text { SD }\end{array}$ & 5 & 3.3 & 4 & 2.6 \\
\hline Medium & $\bar{X}$ hipothetics $-0.5 \mathrm{SD}<\mathrm{X}<\bar{X}+0.5 \mathrm{SD}$ & 40 & 26.5 & 33 & 21.9 \\
\hline High & $\bar{X}$ hipothetics $+0.5 \mathrm{SD}<\mathrm{X}<\bar{X}+1.5 \mathrm{SD}$ & 68 & 45 & 75 & 49.7 \\
\hline $\begin{array}{l}\text { Very } \\
\text { High }\end{array}$ & $\bar{X}_{\text {hipothetics }}>1.5 \mathrm{SD}$ & 38 & 25.2 & 39 & 25.8 \\
\hline
\end{tabular}

\section{Experimental Group and Control Group}

Each of the control group and the experimental (treated) group was selected in pairs based on the similarity of thescores pretest they obtained. This was done to ensure that the research subjects from both the control group and the experimental group departed from the same conditions. Table 4 below shows the pair scores between the experimental and control group members.

Table 4. Scores for Pretest Experimental and Control Groups for Innovative Behavior Intention Variables

\begin{tabular}{cccc}
\hline \multicolumn{2}{c}{ Treated (experimental) Group } & \multicolumn{2}{c}{ Control Group } \\
\hline Respondent \# & $\begin{array}{c}\text { Behavior } \\
\text { Intentions Scores }\end{array}$ & Respondent \# & $\begin{array}{c}\text { Behavior Intentions } \\
\text { Scores }\end{array}$ \\
\hline 75 & 36 & 11 & 36 \\
86 & 42 & 44 & 42 \\
49 & 30 & 55 & 30 \\
36 & 38 & 53 & 38 \\
140 & 30 & 37 & 31 \\
35 & 34 & 91 & 34 \\
58 & 36 & 46 & 37 \\
32 & 40 & 16 & 40 \\
30 & 40 & 132 & 40 \\
31 & 36 & 101 & 35 \\
54 & 34 & 91 & 37 \\
84 & 40 & 53 & 39 \\
92 & 36 & Average Score for Behavior & 36 \\
\hline Average Score for Behavior & 36.31 & Intentions Scores for & 36.62 \\
Bntentions Scores for & \multicolumn{3}{c}{ Behavior Intention } \\
\hline
\end{tabular}


Average score for Pretest Intention for Innovative Behavior the experimental group and the control group were relatively equal. The difference in the average score is relatively small that is equal to 0.31 which is not significant.

Table 5. Scores for Pretest Experimental and Control Groups for Creativity Variables

\begin{tabular}{cccc}
\hline \multicolumn{2}{c}{ Treated (experimental) Group } & \multicolumn{2}{c}{ Control Group } \\
\hline Respondent \# & $\begin{array}{c}\text { Creativity } \\
\text { scores }\end{array}$ & Respondent \# & Creativity scores \\
\hline 75 & 68 & 11 & 68 \\
86 & 61 & 44 & 62 \\
49 & 55 & 55 & 56 \\
36 & 57 & 53 & 59 \\
140 & 57 & 37 & 56 \\
35 & 60 & 91 & 62 \\
58 & 60 & 46 & 63 \\
32 & 68 & 16 & 68 \\
30 & 57 & 132 & 59 \\
31 & 68 & 101 & 67 \\
54 & 61 & 91 & 62 \\
84 & 66 & 27 & 64 \\
92 & 60 & 53 & 59 \\
Average Score for Pretest & 61.38 & Average Score for Pretest \\
Intention & \multicolumn{4}{l}{ Intention } \\
\hline
\end{tabular}

The average score of pretest creativity between the experimental group and the control group is relatively equal. The difference in the average score is relatively small at 0.54 which is not a significant value.

\section{Design Thinking Training}

Thirteen people in the experimental group were treated with training of Design Thinking. This training was arranged based on the process of Design Thinking. Material of design thinking is delivered by explaining the concept of design thinking, giving examples of how design thinking is done, and simulating the process design thinking. The entire training material is carried out interactively. After the entire training material is delivered the trainer gives assignments to participants. Participants in groups are given a design challenge that is a banner laundry with a lot of weaknesses in terms of design. Participants are asked to improve the design banner by using the process design thinking. The time given to complete this challenge is 1 week. The results of the process are design thinking then presented by participants in front of the trainer. In this presentation, participants explained the results of the process design thinking they had done. The final result of this presentation is a banner that has improved the design quality.

\section{Post-test: The Experiment Group and the Control Group}

Posttest were conducted on the research subjects, namely the experimental group and the control group. The posttest given is the same as the pretest by giving an intention questionnaire of innovative behavior and creativity. The average posttest score of creativity between the different experimental groups. The score of the experimental group is higher than the score of the creativity of the control group. The difference in scores between the two groups was 1.55 . 
Table 6. Scores for Posttest Experimental and Control Groups for Creativity Variables

\begin{tabular}{cccc}
\hline \multicolumn{2}{c}{ Treated (experimental) Group } & \multicolumn{2}{c}{ Control Group } \\
Respondent \# & $\begin{array}{c}\text { Creativity } \\
\text { scores }\end{array}$ & Respondent \# & Creativity scores \\
\hline 75 & 70 & 11 & 58 \\
86 & 70 & 44 & 69 \\
49 & 60 & 55 & 41 \\
36 & 76 & 53 & 72 \\
140 & 64 & 37 & 57 \\
35 & 54 & 91 & 70 \\
58 & 64 & 46 & 57 \\
32 & 63 & 16 & 67 \\
30 & 66 & 132 & 51 \\
31 & 55 & 101 & 70 \\
54 & 65 & 91 & 76 \\
84 & 64 & 27 & 72 \\
\hline 2 & 65 & 53 & 62.76 \\
\hline
\end{tabular}

Average score of post-test intention innovative behavior between different experimental groups. The average posttest intention score of the experimental group's innovative behavior was higher than the score of the control group creativity. The difference between the two groups' scores was 4.23.

Table 7. Scores for Posttest Experimental and Control Groups for Innovative Behavior Intention

\begin{tabular}{cccc}
\hline \multicolumn{2}{c}{ Treated (experimental) Group } & \multicolumn{2}{c}{ Control Group } \\
\hline \multirow{2}{*}{ Respondent \# } & $\begin{array}{c}\text { Creativity } \\
\text { scores }\end{array}$ & Respondent \# & Creativity scores \\
\hline 75 & 43 & 11 & 37 \\
86 & 46 & 44 & 34 \\
49 & 35 & 55 & 32 \\
36 & 44 & 53 & 33 \\
140 & 40 & 37 & 26 \\
35 & 38 & 91 & 30 \\
58 & 37 & 46 & 43 \\
32 & 35 & 16 & 44 \\
30 & 43 & 132 & 25 \\
31 & 31 & 101 & 37 \\
54 & 40 & 91 & 38 \\
84 & 40 & 27 & 39 \\
92 & 41 & 53 & 40 \\
\hline
\end{tabular}

Scores of posttest intentional innovative behavioral intentions between different experimental groups. The average posttest intention score of the experimental group's innovative behavior was higher than the score of the control group creativity. The difference between the two groups' scores was 4.23. 


\section{Normality Test Results}

Normality test with Shapiro-Wilk obtained significance values of 0.485 and 0.201 . Because the significance value is above 0.05 , the data distribution is normal. Thus, the parametric test can be performed t-test free sample. The normality test was also carried out on the score of post test the intention variable of the innovative behavior of the experimental group and the control group using Shapiro-Wilk analysis. Normality test results showed a significance value of 0.893 and 0.780 . With this value, it can be concluded that the data are normally distributed because the values are above 0.05 . Thus the parametric can be carried out test t-test of the free sample

\section{Discussion}

The average score of the creativity of the experimental group before being subjected to training is 61.38 and after being subjected to training of Design Thinking is 64.31. This shows an increase in creativity after being treated by training of Design Thinking.

Table 8 Table Score Comparison of Pretest and Posttest Scores for Experiment Group

\begin{tabular}{cccc}
\hline No & Respondent \# & Pretest & Posttest \\
\hline 1 & 75 & 68 & 70 \\
2 & 86 & 61 & 70 \\
3 & 49 & 55 & 60 \\
4 & 36 & 57 & 76 \\
5 & 140 & 57 & 64 \\
6 & 35 & 60 & 54 \\
7 & 58 & 60 & 64 \\
8 & 32 & 68 & 63 \\
9 & 30 & 57 & 66 \\
10 & 31 & 68 & 55 \\
11 & 54 & 61 & 65 \\
12 & 84 & 66 & 64 \\
13 & 92 & 60 & 65 \\
\hline \multicolumn{4}{c}{} \\
\hline
\end{tabular}

Using the t-test paired sample, the creativity scores of the experimental group prior to training and after training were not significant differences. The significance score is 0.216 below 0.05 . Thus, it can be concluded that training Design Thinking does not have a real influence in increasing creativity. Thus, alternative hypothesis 1 which states "There are differences in intentions of innovative behavior between before and after being subjected to the treatment of Design Thinking Training" is not supported.

Table 9 Paired Sample T-test Test Table Pretest and Postest Score Creativity Group Experiments

\begin{tabular}{|c|c|c|c|c|c|c|c|}
\hline & & \multicolumn{3}{|c|}{ Paired Differences } & $\mathrm{t}$ & df & $\begin{array}{l}\text { Sig. (2- } \\
\text { tailed) }\end{array}$ \\
\hline & & \multicolumn{3}{|c|}{$\begin{array}{l}\text { 95\% Confidence Interval of } \\
\text { the Difference }\end{array}$} & & & \\
\hline & & Mean & Lower & Upper & & & \\
\hline Pair 1 & $\begin{array}{l}\text { Creative_PRE - } \\
\text { Creative_POST }\end{array}$ & -2.92308 & -7.79793 & 1.95178 & -1.306 & 12 & .216 \\
\hline
\end{tabular}

Hypothesis testing results that once Design thinking is not quality in improving the creativity of the participants ever. This is possible due to lack of strong intrinsic motivation from the participants ever. As expressed by Robbins and Judge (2011), retail creativity essentially requires expertise, a creative 
thinking, and intrinsic motivation to the task. The absence of intrinsic motivation assignment causes a lack of UDI for creative thinking. Intrinsic motivation is a motivation that is driven by deep interest in the characteristics of the task being performed. The participants once Mauri the design challenge as a task and not as an interesting challenge to work on. The feeling of translating this is what then causes the creativity to be less developed.

The second hypothesis states that the "There is a difference in the post-test scores of intentions of innovative behave between the experimental groups that are subject to the ever design treatment of thinking with a control group that is not subject to design thinking Plus".

Table 10. T-Test for Free Samples Scores Posttest Variable Intentional Behavior Innovative between Experiment Group and Control Group

t-test for Equality of Means

95\% Confidence Interval of the

Difference

\begin{tabular}{|c|c|c|c|c|c|}
\hline & & $\mathrm{t}$ & $\mathrm{df}$ & $\begin{array}{l}\text { Sig. (2- } \\
\text { tailed) }\end{array}$ & Mean Difference \\
\hline \multirow{2}{*}{$\begin{array}{l}\text { EKS } \\
\text { INNOV }\end{array}$} & Equal variances assumed & 2.099 & 24 & .046 & 4.23077 \\
\hline & $\begin{array}{l}\text { Equal variances not } \\
\text { assumed }\end{array}$ & 2.099 & 21.602 & .048 & 4.23077 \\
\hline
\end{tabular}

The free sample T-test test between the innovative behaved intense score between the experimental group and the control group resulted in a significance value of 0.48 . The value is above 0.05 so it can be concluded there is a significant difference in scores to the two groups. Thus, the two hypotheses were supported.

The effectiveness of Design Thinking training in improving the intention of innovative behaviour can be seen from the difference in the Pretests score (prior to training) in experimental groups with posttest scores (after training). Through the sample T-Test in pairs obtained a significance value of 0.024 . The significance value below 0.05 indicates that there is a significant difference between the pretests score and its posttest. Thus, it can be concluded that Design Thinking training is effective in enhancing the intention of innovative behave

Table 11. Table test sample T-Test pairs Pretest score and Posttest Intentional Behavior Innovative group experiments

Sig. (2-

Paired Differences

$\mathrm{t}$ df tailed)

\begin{tabular}{|c|c|c|c|c|c|c|c|}
\hline & \multirow{4}{*}{$\begin{array}{l}\text { INNOV_PRE - } \\
\text { INNOV_POST }\end{array}$} & \multirow{4}{*}{$\begin{array}{c}\text { Mean } \\
-3.15385\end{array}$} & \multirow{3}{*}{$\begin{array}{c}\text { Std. } \\
\text { Deviation } \\
4.41298\end{array}$} & \multicolumn{2}{|c|}{$\begin{array}{l}5 \% \text { Confidence Interval of } \\
\text { the Difference }\end{array}$} & \multirow[b]{3}{*}{-12} & \multirow{4}{*}{.024} \\
\hline & & & & Lower & Upper & & \\
\hline & & & & -5.82058 & -.48711 & & \\
\hline & & & & & & 2.577 & \\
\hline
\end{tabular}

Innovation is a multistage process. In the early stages of innovation, individuals need to look for problems and then they gather knowledge related to innovation and try to find out the original solution to solve the problem. During the third stage, an innovative individual seeks sponsorship for an idea and attempts to build a coalition of supporters for it finally, at the last stage, the individual transforms the idea or solution into a useful application that can Mass-produced (Wattanasupachoke, T, 2012). 
Wang (2014) explains that factors affecting the intention of innovative intentions such as liberalists (freedom) in expressing ideas and solutions affect the intention to behave innovatively. In the process of design thinking, individuals have the freedom to find solutions to the challenges faced by them. With such freedom, according to the findings of Wang (2014) then the intention to behave innovative in the process of design thinking, the individual will increase.

\section{Conclusion}

Based on the results of the testing of the hypothesis, several conclusions that can be taken is as follows. First, there is no significant difference in the creativity score between before and after being subject to Design Thinking training treatment. With the unsupported hypothesis, it can be concluded that Design Thinking training imposed on the experimental group is ineffective in enhancing the creativity of the trainees. Second, there is a significant difference in the innovative behavior scores before and after being subject to Design Thinking training treatment. Design Thinking Training imposed on the experimental group proved to be effective in enhancing the intention of innovative behavior.

From the implementation of research that has been done then the author suggests the following things. First, motivation factor is very important in the implementation of training. Participants who are motivated to attend training will get good results compared to those who are less motivated. Thus, the next researcher must ensure and encourage the motivation of the trainees. Second, measuring instruments used for measuring are questionnaires which are self-assessment methods. Researchers are then able to use the more objective measuring instruments in measuring variable creativity e.g. using a creative assay. Third, with the evidence of Design Thinking training in improving the intention of innovative behave then the authors suggest that Design Thinking is applied as an alternative technique of learning to students or learners. It is important to encourage students to actively think of creating innovations. Fourth, researchers can further expand the field of application of design thinking not only on design issues but can test the application of Design thinking on other areas.

\section{References}

Ajzen, I. and Fishbein, M. (1975), "Belief, Attitude, Intention, and Behavior", An Introduction to Theory and Research, pp. 129-385.

Cox, S.. (2005), Review of Creativity in Business: Building on the UK'sstrengths .

Ersoy, E. and Baser, N. (2014), "The effects of problem-based learning method in higher education on creative thinking", Procedia-Social and Behavioral Sciences, Vol. 116, pp. 3494-3498.

Marušić, M. and Sliško, J. (2014), "High-School Students Believe School Physics Helps in Developing Logical But not Creative Thinking: Active Learning Can Change This Idea", European J of Physics Education, Vol. 5 No. 4.

OECD. (2005), Guidelines for Collecting and Interpreting Innovation Data. Third Edition.

Robbins, S.. and Judge, T.. (2011), Perilaku Organisasi, Salemba Empat, Jakarta.

Robinson, S.L. and R. J. Bennett. (1995), "No Title", Academy of Management Journal, Vol. 8, pp. 555572.

Steinbeck, R. (2011), "Building Creative Competence in Globally Distributed Courses through Design Thinking. Comunicar”, Scientific Journal of Media Literacy, Vol. 37, v, XIX No. v, pp. 27-34.

Wang, C.. (2014), "A Longitudinal Study of Innovation Competence and Quality Management on Firm Performance", Journal Innovation: Management, Policy, \& Practice, Vol. 16 No. 3.

Wattanasupachoke, T. (2012), "Design Thinking, Innovativeness and Performance: An Empirical Examination”, International Journal of Management and Innovation, Vol. 4 No. I. 